\title{
EVALUATION OF THE VARIOUS CLINICAL PRESENTATIONS OF ADULT CNS TUBERCULOSIS
}

\author{
JOY KMNI ${ }^{1}$, KUNDU NC ${ }^{2}$, AKHTER ${ }^{3}$, HOSSAIN MZ ${ }^{4}$, RAHMAN AHMW ${ }^{5}$, RAHMAN MM ${ }^{6}$, \\ SAIFULLAH $\mathrm{M}^{7}$, ROUF MA ${ }^{8}$, HAQUE $\mathrm{MM}^{9}$
}

\begin{abstract}
:
Background: Central nervous system (CNS) involvement is one of the most important extrapulmonary manifestations of tuberculosis (TB) causing considerable mortality and morbidity. Presentations of CNS TB are extremely variable. Treatments are generally more effective if the disease can be detected early. This study is to find out the various clinical patterns and investigation findings that might help in early detection of CNS TB.
\end{abstract}

Objective: This study was conducted to detect various clinical manifestations of adult CNS TB at an earlier stage of evaluation.

Methods: This was a hospital based observational study (cross sectional type) conducted on 30 patients of CNS TB who were admitted in Sir Salimullah Medical College Mitford Hospital, Dhaka during a period of 6 months from October 2013 to April 2014.

Results: Among the participants 53\% were male and $47 \%$ were female, with a male female ratio

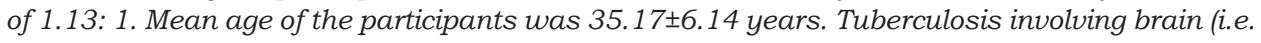
cranial TB) was most common (30.4\%) in 15-24 years age group whereas spinal form of TB was most common (42.8\%) in 25-34 years age group. Mean age of the participants having Brain TB was $36.46 \pm 6.90$ years. Mean age of the participants having spinal TB was $32.36 \pm 12.52$ years. Highest number of the cranial forms of TB was tuberculoma (52.2\%) in this study and was found mostly in the young adults. Spinal TB was found in 25-34 years age group in highest number, all but one were Potts disease. Tuberculoma and tuberculous meningitis had an equal distribution in female sex while males had a higher (53.8\%) occurrence of tuberculoma. On the other hand, spinal involvement was commoner in male sex (43.5\%).Fever was the most common symptom noted in all forms of CNS TB patients $(78.26 \%$ for brain and $71.43 \%$ for spinal cord TB patients) followed by headache and loss of consciousness representing $2^{\text {nd }}$ and $3^{\text {rd }}$ common symptom in brain TB patients. Most common clinical signs in brain TB were signs of meningeal irritation (65.22\%), cranial nerve palsies and papillodema while spastic paraparesis with sensory level being the commonest in spinal cases. Tuberculoma was the most frequent neuro-radiologic findinds in case of brain TB patients and paraspinal soft tissue shadow with vertebral collapse was commoner in spinal TB patients.

Conclusion: This study has highlighted the relative frequency of various types of brain and spinal TB lesions along with the symptoms, signs and laboratory findings in Bangladeshi adult patients. In Bangladesh, tuberculosis should be always an important differential diagnosis in patients of fever with headache as well as spastic paraplegia or quadriplegia for any duration in any sex group.

Key words: Adult CNS TB, Brain TB, Spinal TB

J Dhaka Med Coll. 2019; 28(1) : 76-84

1. Dr. KM Nazmul Islam Joy, Junior Consultant, Department of Medicine, Government Staff Hospital, Fulbaria, Dhaka

2. Dr. Narayan Chandra Kundu, Associate Professor, Department of Neurology, Shaheed Suhrawardy Medical College \& Hospital, Sher-E-Bangla Nagar, Dhaka-1207

3. Dr. Mahfuza Akhter, OSD, DGHS attached to Dhaka Medical College \& Hospital, Dhaka

4. Dr. Mohammad Zaid Hossain, Associate Professor, Department of Medicine, Dhaka Medical College, Dhaka

5. Dr. Abu Hayat Mohammad Waliur Rahman, Consultant, Medicine

6. Dr. Md. Mizanur Rahman, Associate Professor \& Head, Department of Medicine, Tairunnessa Memorial Medical College, Gazipur

7. Dr. Md. Saifullah, Assistant Professor of Medicine, Dhaka Medical College, Dhaka

8. Dr. Mohammad Abdur Rouf, Post graduate Trainee, Dhaka Medical College, Dhaka

9. Dr. Mohammad Majharul Haque, Junior Consultant Medicine, Narayangonj General Hospital, Dhaka

Correspondence : Dr. KM Nazmul Islam Joy, Junior Consultant, Department of Medicine, Government Staff Hospital, Fulbaria, Dhaka- 1000

Received: 10 February 2019

Revision: 02 March 2019

Accepted: 30 Mach 2019

DOI: https://doi.org/10.3329/jdmc.v28i1.45760 


\section{Introduction}

Tuberculosis (TB) remains a major global problem and is one of the leading causes of infection-related mortality across the world (Nicholas A et al 2009). Central nervous system (CNS) involvement is noted in 5 to $10 \%$ of extra pulmonary TB cases, and accounts for approximately $1 \%$ of all TB cases. (Cherian A et al 2011).TB meningitis accounts for $0.5-1 \%$ of tuberculosis disease and intra-cranial tuberculomas which on a global level account for up to $40 \%$ of 'brain tumors' (Jacobs R.F.et al 2003, Jain S.K.et al 2005)·CNS TB carries a high mortality and a distressing level of neurological morbidity. The incidence of CNS tuberculosis is directly proportional to the prevalence of tuberculous infection in general (Garg R.K. 1999).

In recent times, there has been a resurgence of tuberculosis in both developing and developed countries. Risk factors include the increasing prevalence of HIV infection, over-crowding in the urban population, poor nutritional status, appearance of drug-resistant strains of tuberculosis and an increase in migration from countries where tuberculosis is prevalent to the developed world (Garg R.K. 1999).

Several studies has been done to find out presentation, diagnosis, treatment and outcomes of Tuberculous Meningitis (TBM) cases in various countries of the world, but various aspects of CNS TB as a whole, which is not always necessarily cases of TBM, are yet to be evaluated. CNS TB can be defined as tuberculous involvement of the brain and spinal cord.Granulomatous inflammation of the CNS by the Mycobacterium tuberculosis may involve the meninges, brain, spinal cord and the bones covering the brain and spinal cord, and its manifestations clinically depends on the specific location of the disease process (Trivedi $\mathrm{R}$ et $\mathrm{al}$ 2009). Hence, it is difficult to classify the varied manifestations of CNS TB. However, it can be classified into two major forms-one is Intracranial CNS TB, the other one is Spinal TB. Intracranial TB is further classified into five forms-

- Tuberculous meningitis (TBM)

- Tuberculous encephalopathy

- Tuberculous vasculopathy
- CNS tuberculoma (single or multiple)

- Tuberculous Brain Abscess

Spinal TB is again classified into three forms-

- Pott's spine and Pott's paraplegia

- Non-osseous spinal tuberculoma

- Spinal meningitis (Garg R.K. 1999).

Each of the forms has distinct pathology, clinical features and characteristic laboratory, imaging and histopathological or cytological findings that lead to diagnosis.

In Bangladesh, little work has been done to assess the various presentations of CNS TB. The study aimed at diagnosing various forms of CNS TB common in Bangladesh, with feasible diagnostic tools in hand, and thus focusing on the fact that CNS TB is diverse in its presentation and early diagnosis of this devastating disease is necessary for starting early treatment to reduce morbidity and mortality.

\section{Materials \& methods:}

This study was an observational study (Cross sectional type) \& was carried out in different units of Medicine and Neurology Departments of Sir Salimullah Medical College and Mitford Hospital, Dhaka, over a period of 6 months from October 2013 to April 2014. All adult patients who have clinical diagnosis of CNS Tuberculosis (as per operational definition) hospitalized in medicine and neurology wards of Sir Salimullah Medical College and Mitford Hospital, Dhaka; during the study period were the study population.

\section{Eligibility criteria:}

\section{Inclusion criteria:}

- Both male and female from all ethnic origin, age more than 15 years.

- All patients who have compatible clinical features along with diagnostic investigation findings suggesting CNS TB.

\section{Exclusion criteria:}

- Patients whose clinical features were compatible with CNS tuberculosis but supportive investigations (e.g., imaging, MT, CSF study etc) did not suggest TB. 
- Not willing to give informed consent (by patient or relatives)

\section{Operational definitions:}

A. CNS TB:

Either intracranial or spinal or both forms of TB cases which fulfil the following clinical, imaging or cytological criteria.

\section{Tuberculous Meningitis (TBM):}

Clinical

a. fever and headache (for more than 14 days)

b. vomiting

c. altered sensorium or focal neurological deficit

\section{CSF}

- pleocytosis (more than 20 cells, more than $60 \%$ lymphocytes)

- increased proteins (more than $100 \mathrm{mg} / \mathrm{dl}$ ) $\&$ low sugar (less than $60 \%$ of corresponding blood sugar)

- positive CSF culture for M.tuberculosis/ positive ADA test/ PCR (Polymerase Chain Reaction) positive for M.tuberculosis.

\section{Imaging}

- exudates in basal cisterns or in sylvian fissure hydrocephalus

- infarcts (basal ganglionic)

- gyral enhancement

- tuberculoma formation

\section{Evidence of tuberculosis elsewhere}

- Chest X-ray (CXR)-apical opacity/cavitations

- Sputum for AFB positive

- Positive granulomatous inflammation with caseation and epithelioid cells in lymph node biopsy. (Ahuja GK et al 1994).

\section{Tuberculous vasculopathy:}

Patient presenting with features of focal deficits like hemiplegia/aphasia etc. and CT scan evidence of ischemia along with other features of tuberculosis.

\section{Intracranial tuberculoma:}

Clinical:

- Low-grade fever, headache vomiting, seizures, focal neurological deficit \& papilloedema (characteristic of supratentorial tuberculomas).

- Brainstem syndromes, cerebellar manifestations, and multiple cranial nervepalsies (Intratentoria 1tuberculoma) (TalamasO et al 1989,Rajshekhar V et al 1997, Vengsarkar US et al 1986)

\section{Imaging}

- On CT, tuberculomas are characterized as low- or high-density and rounded or lobulated masses and show intense homogenous or ring enhancement after contrast administration.

\section{Pott's spine and Pott's paraplegia:}

\section{Clinical}

- Local pain, tenderness over the affected spine or overlying bony deformity in the form of gibbus.

- Acute or subacute, progressive, spastic type of sensorimotor paraparesis.

\section{Imaging}

- Dorsal spinal X-ray/MRI spine demonstrating the destruction of adjacent vertebral bodies and intervening disc spaces.

- CT-guided needle biopsy to establish tuberculosis.

\section{Non-osseous spinal cord tuberculosis:}

- The clinical features are indistinguishable from those of any extramedullary or intramedullary tumor.

- MRI is the investigation of choice for these lesions.

\section{Study Procedure:}

Diagnosis of various types of CNS TB was done on the basis of compatible clinical features and associated consistent imaging (Chest X-ray, CT scan/ MRI of Brain, MRI of spines) and CSF 
findings. Cytological examination was done from paraspinal masses in case of spinal TB or where accessible lymph nodes were found (in case of Cranial TB).Biopsy and histopathological examination from brain lesion was not feasible. A structured data collection form was developed containing all the variables of interest. Data were collected by interview, observation, clinical examination and investigations.

Statistical Analysis:

Statistical analyses were carried out by using the Statistical Package for Social Sciences version 16.0 for Windows (SPSS Inc., Chicago, Illinois, USA). Continuous variables were expressed as mean, standard deviation, and categorical variables as frequencies and percentages.

\section{Ethical Consideration:}

Prior to the commencement of this study, the research protocol was approved by the local ethical committee.

\section{Results:}

A total of 30 patients were included in the study. Mean age of the participants was $35.17 \pm 6.14$ years. Tuberculosis involving brain (i.e. cranial TB) was most common (30.4\%) in 15-24 years age group whereas spinal form of TB was most common $(42.8 \%)$ in $25-34$ years age group (Table I) Mean age of the participants having Brain TB was $36.46 \pm 6.90$ years. Mean age of the participants having spinal TB was $32.36 \pm$ 12.52 years. Highest number of the cranial forms of TB was tuberculoma (52.2\%) in this study and was found mostly in the young adults (Table II). Spinal TB was found in 25-34 years age group in highest number, all but one were Potts disease. (Table III) 53\% of participants were male $\& 47 \%$ were female, with a male female ratio of 1.13: 1.(Table IV). Tuberculoma and tuberculous meningitis had an equal distribution in female sex while males had a higher $(53.8 \%)$ occurrence of tuberculoma (Table VI). On the other hand, spinal involvement was commoner in male sex (43.5\%) which was Pott's disease. (Table VII).

\section{Table I}

Distribution of the study patients by age $(n=30)$

\begin{tabular}{lcc}
\hline $\begin{array}{l}\text { Age of } \\
\text { participants }\end{array}$ & \multicolumn{2}{c}{ Pattern of CNS TB } \\
& $\mathrm{n}=23$ & $\mathrm{n}=07$ \\
\hline $15-24$ & $07(30.4 \%)$ & $02(28.6 \%)$ \\
$25-34$ & $04(17.4 \%)$ & $03(42.8 \%)$ \\
$35-44$ & $05(21.7 \%)$ & $00(0 \%)$ \\
$45-54$ & $03(13.04 \%)$ & $02(28.6 \%)$ \\
$55-64$ & $04(17.4 \%)$ & $00(0 \%)$ \\
Mean $\pm \mathrm{SD}$ (years) & $36.46 \pm 6.90$ & $32.36 \pm 12.52$ \\
\hline
\end{tabular}

Table II

Age distribution of various Brain TB lesions $(n=23)$

\begin{tabular}{lccc}
\hline $\begin{array}{l}\text { Age of the } \\
\text { participants }\end{array}$ & \multicolumn{3}{c}{ Type of brain TB } \\
(years) & $\mathrm{n}=11$ & $\mathrm{n}=12$ & $\mathrm{n}=23$ \\
\hline $15-24$ & $03(27.3 \%)$ & $04(33.3 \%)$ & $07(30.4 \%)$ \\
$25-34$ & $02(18.2 \%)$ & $02(16.7 \%)$ & $04(17.4 \%)$ \\
$35-44$ & $04(36.4 \%)$ & $01(8.3 \%)$ & $05(21.8 \%)$ \\
$45-54$ & $00(0 \%)$ & $03(25 \%)$ & $03(13.04 \%)$ \\
$55-64$ & $02(18.2 \%)$ & $02(16.7 \%)$ & $04(17.4 \%)$ \\
\hline
\end{tabular}

Fever was the most common symptom noted in all forms of CNS TB patients $(78.26 \%$ for brain and $71.43 \%$ for spinal cord TB patients) followed by headache and loss of consciousness representing $2^{\text {nd }}$ and $3^{\text {rd }}$ common symptom in brain TB patients.(Table VIII). Paralysis of lower limbs (71.43\%) \& low back pain (42.86\%) are the major symptoms in spinal TB patients after fever. (Table IX). Most common clinical signs in brain TB were signs of meningeal irritation (65.22\%), cranial nerve palsies and papillodema while spastic paraparesis with sensory level being the commonest in spinal cases.(Table XI $\&$ XII)

In case of cranial tuberculosis, the duration of presenting symptoms were mostly in the range of 7 days to one month. $39.13 \%$ patients 
presented with a history of 7-14 days illness $\&$ longer duration of presenting symptoms ( $>2$ months) was more observed in cases of spinal TB (42.86\%). (Table X)

\section{Table III}

Age distribution of various Spinal TB lesions $(n=07)$

\begin{tabular}{lccc}
\hline $\begin{array}{l}\text { Age of the } \\
\text { participants } \\
\text { (years) }\end{array}$ & \multicolumn{3}{c}{ Type of spinal TB lesions } \\
$\begin{array}{c}\text { Pott's } \\
\text { Disease } \\
\text { n=06 }\end{array}$ & $\begin{array}{c}\text { Non-osseous } \\
\text { spinal TB } \\
n=01\end{array}$ & $\begin{array}{c}\text { Total } \\
\text { n=07 }\end{array}$ \\
\hline $15-24$ & $02(33.3 \%)$ & $00(0 \%)$ & $02(28.6 \%)$ \\
$25-34$ & $03(50 \%)$ & $00(0 \%)$ & $03(42.9 \%)$ \\
$35-44$ & $00(0 \%)$ & $00(0 \%)$ & $00(0 \%)$ \\
$45-54$ & $01(16.7 \%)$ & $01(100 \%)$ & $02(28.6 \%)$ \\
$55-64$ & $00(0 \%)$ & $00(0 \%)$ & $00(0 \%)$ \\
\hline
\end{tabular}

Table IV

Sex distribution of the participants in respect of age $(n=30)$

\begin{tabular}{lccc}
\hline $\begin{array}{l}\text { Age of the } \\
\text { participants }\end{array}$ & \multicolumn{3}{c}{ Male of the participants } \\
(years) & $\mathrm{n}=16$ & $\mathrm{n}=14$ & $\mathrm{n}=30$ \\
\hline $15-24$ & $01(6.3 \%)$ & $08(57.1 \%)$ & $09(30 \%)$ \\
$25-34$ & $06(37.5 \%)$ & $01(7.1 \%)$ & $07(23.3 \%)$ \\
$35-44$ & $02(12.5 \%)$ & $03(21.4 \%)$ & $05(16.7 \%)$ \\
$45-54$ & $03(18.8 \%)$ & $02(14.3 \%)$ & $05(16.7 \%)$ \\
$55-64$ & $04(25 \%)$ & $00(0 \%)$ & $4(13.3 \%)$ \\
\hline
\end{tabular}

Table V

Sex distribution of the participants $(n=30)$

\begin{tabular}{lcc}
\hline Type of CNS TB & \multicolumn{2}{c}{ Sex of the participants } \\
\cline { 2 - 3 } & Male $\mathrm{n}=23$ & Female $\mathrm{n}=07$ \\
\hline Brain TB & $13(56.5 \%)$ & $04(57.1 \%)$ \\
Spinal TB & $10(43.5 \%)$ & $03(42.9 \%)$ \\
\hline
\end{tabular}

Table VI

\begin{tabular}{lccc}
\multicolumn{4}{c}{ Sex distribution of Brain TB $(n=23)$} \\
\hline \multirow{3}{*}{$\begin{array}{l}\text { Type of Brain } \\
\text { TB }\end{array}$} & Male & Female & Total \\
& $\mathrm{n}=13$ & $\mathrm{~N}=10$ & $\mathrm{n}=23$ \\
\hline TBM & $06(46.4 \%)$ & $05(50.0 \%)$ & $11(47.8 \%)$ \\
Tuberculoma & $07(53.8 \%)$ & $05(50.0 \%)$ & $12(52.2 \%)$ \\
\hline
\end{tabular}

Table VII

Sex distribution of spinal TB $(n=07)$

\begin{tabular}{lccc}
\hline \multirow{2}{*}{$\begin{array}{l}\text { Type of spinal } \\
\text { TB }\end{array}$} & \multicolumn{3}{c}{ Sex of the participants } \\
\cline { 2 - 4 } & Male & Female & Total \\
& $\mathrm{n}=04$ & $\mathrm{n}=03$ & $\mathrm{n}=07$ \\
\hline Pott's Disease & $04(100 \%)$ & $02(66.7 \%)$ & $06(85.7 \%)$ \\
Non-osseous & $00(0 \%)$ & $01(33.3 \%)$ & $04(14.3 \%)$ \\
spinal TB & & & \\
\hline
\end{tabular}

\section{Table VIII}

Distribution of patients having Brain TB according to presenting Symptoms $(n=23)$ *

\begin{tabular}{lcc}
\hline Symptoms & No. of cases & Percentage \\
\hline Fever & 18 & $78.26 \%$ \\
Headache & 16 & $69.57 \%$ \\
Loss of consciousness & 08 & $34.78 \%$ \\
Vomiting & 07 & $30.43 \%$ \\
Vertigo & 04 & $17.40 \%$ \\
Cognitive impairment & 03 & $13.04 \%$ \\
Convulsion & 02 & $8.70 \%$ \\
Double vision & 04 & $17.40 \%$ \\
Non-productive cough & 02 & $8.70 \%$ \\
Hemiparesis H/0 & 01 & $4.35 \%$ \\
contact with known TB & & \\
H/O previous TB & 02 & $8.70 \%$ \\
(Rx completed) & & \\
Weakness, weight & 03 & $13.04 \%$ \\
loss, malaise etc. & & \\
\hline
\end{tabular}

*Values are not mutually exclusive

Table IX

Distribution of patients having Spinal TB according to presenting Symptoms $(n=07)$ *

\begin{tabular}{lcc}
\hline Symptoms & No. of cases & Percentage \\
\hline Fever & 05 & $71.43 \%$ \\
Paralysis of lower limbs & 05 & $71.43 \%$ \\
Low back pain & 03 & $42.86 \%$ \\
Incontinence of urine & 03 & $42.86 \%$ \\
Bone pain & 01 & $14.28 \%$ \\
H/O previous TB & 01 & $14.28 \%$ \\
(Rx completed) & & \\
\hline
\end{tabular}

*Values are not mutually exclusive 
Table X

Duration of presenting symptoms in brain \& spinal TB $(n=30)$

\begin{tabular}{lcc}
\hline $\begin{array}{l}\text { Duration of } \\
\text { symptoms }\end{array}$ & $\begin{array}{c}\text { Cases of } \\
\text { brain TB (\%) }\end{array}$ & $\begin{array}{c}\text { Cases of } \\
\text { spinal TB(\%) }\end{array}$ \\
\hline 7-14 days & $09(39.13 \%)$ & $01(14.29 \%$ \\
$15-30$ days & $09(39.13 \%)$ & $02(24.57 \%$ \\
31-60 days & $01(4.35 \%)$ & $01(14.29 \%)$ \\
$>60$ days & $04(17.39 \%)$ & $03(42.86 \%)$ \\
\hline
\end{tabular}

Table XI

Distribution of patients having Brain TB according to clinical signs*

\begin{tabular}{lcc}
\hline Signs & No. of cases & Percentage \\
\hline $\begin{array}{l}\text { Signs of meningeal } \\
\text { irritation }\end{array}$ & 15 & $65.22 \%$ \\
$\begin{array}{l}\text { Cranial nerve } \\
\text { palsies }\left(3^{\text {rd }}, 6^{\text {th }}, 7^{\text {th }}\right)\end{array}$ & 09 & $39.13 \%$ \\
$\begin{array}{l}\text { Papilloedema } \\
\text { (Fundoscopy) }\end{array}$ & 05 & $21.74 \%$ \\
$\begin{array}{l}\text { Optic atrophy } \\
\text { (Fundoscopy) }\end{array}$ & 01 & $4.35 \%$ \\
$\begin{array}{l}\text { Long tract signs } \\
\text { Generalized }\end{array}$ & 04 & $17.40 \%$ \\
lymphadenopathy & 02 & $8.70 \%$ \\
Hepatosplenomegaly & 01 & $4.35 \%$ \\
\hline
\end{tabular}

*Values are not mutually exclusive

Table XII

Distribution of patients having Spinal TB according to clinical signs*

\begin{tabular}{lcc}
\hline Signs & No. of cases & Percentage \\
\hline Spastic paraplegia & 06 & $85.71 \%$ \\
Spastic quadriplegia & 01 & $14.29 \%$ \\
Definite sensory level & 05 & $71.43 \%$ \\
Gibbus & 02 & $28.57 \%$ \\
\hline
\end{tabular}

*Values are not mutually exclusive

High ESR (>50 $\mathrm{mm} 1^{\text {st }}$ hour) was found to be more frequent in spinal forms than the cranial forms, whereas military mottling shadowing and non-homogeneous patchy opacities in both lung fields in chest $\mathrm{X}$ ray were found mostly in cranial TB cases. (Table XIII \& XIV).

\section{Table XIII}

\begin{tabular}{lcc}
\hline Type of CNS TB & Frequency & Percent \\
\hline Brain TB & 09 & $39.13 \%$ \\
Spinal TB & 05 & $71.43 \%$ \\
\hline
\end{tabular}

Distribution of patients of CNS TB based on high $\operatorname{ESR}(n=30)$

Table XIV

Distribution of patients with CNS TB based on CXR P/A appearance $(n=30)$ *

\begin{tabular}{|c|c|c|}
\hline \multicolumn{2}{|c|}{ Appearance in CXR No. of cases } & Percentage \\
\hline $\begin{array}{l}\text { Miliary mottling } \\
\text { shadows }\end{array}$ & 03 & $13.04 \%$ \\
\hline $\begin{array}{l}\text { Patchy opacities in both } \\
\text { lung fields }\end{array}$ & 03 & $13.04 \%$ \\
\hline $\begin{array}{l}\text { Rt Paratacheal } \\
\text { Lymph node }\end{array}$ & 02 & $8.70 \%$ \\
\hline Pleural effusion(mild) & 01 & $4.35 \%$ \\
\hline
\end{tabular}

*Values are not mutually exclusive

Cerebrospinal fluid studies in cases of tuberculous meningirtis revealed a raised ADA level only in $36.36 \%$ cases, along with the standard findings. (Table XV). In only one case of tuberculous meningitis, CSF culture for Mycobacterium tuberculosis became positive. Tuberculoma was the most frequent neuroradiologic findinds in case of brain TB patients and paraspinal soft tissue shadow with vertebral collapse was commoner in spinal TB patients. (Table XVI \& XVII)

Table XV

CSF findings in tuberculous meningitis $(n=11)$ *

\begin{tabular}{lcc}
\hline CSF findings & Frequency & Percent \\
\hline $\begin{array}{l}\text { Lymphocytic } \\
\text { pleocytosis }\end{array}$ & 11 & $100.00 \%$ \\
$\begin{array}{l}\text { High protein (with or } \\
\text { without low sugar conc.) }\end{array}$ & 11 & $100.00 \%$ \\
$\begin{array}{l}\text { ADA level } \\
\begin{array}{l}\text { Positive culture for } \\
\text { M.tuberculosis }\end{array}\end{array}$ & 04 & $36.36 \%$ \\
\hline
\end{tabular}

*Values are not mutually exclusive 
Table XVI

Neuroimaging findings of Brain TB ( $n=23)$ *

CT/MRI appearance

Multiple ring enhancing lesions of variable sizes in

different areas having different intensities(MRI)or densities(CT)

Single large ring like contrast enhancing lesion with

surrounding marked edema

Hydrocephalus

Small infarcts

Meningeal enhancement

Normal imaging

*Values are not mutually exclusive

\begin{tabular}{cc}
$\begin{array}{c}\text { No. of cases } \\
11\end{array}$ & $\begin{array}{c}\text { Percentage } \\
47.82 \%\end{array}$ \\
01 & $4.35 \%$ \\
& \\
02 & $8.70 \%$ \\
02 & $8.70 \%$ \\
01 & $4.35 \%$ \\
04 & $17.40 \%$ \\
\hline
\end{tabular}

Table XVII

Neuroimaging findings of Spinal TB $(n=07)$ *

\begin{tabular}{lcc}
\hline CT/MRI appearance & No. of cases & Percentage \\
\hline $\begin{array}{l}\text { Paraspinal mass with vertebral fracture and reduction of } \\
\text { joint space causing cord compression }\end{array}$ & 06 & $85.71 \%$ \\
Multiple tubercular lesions at retro spinal soft tissue & 01 & $14.29 \%$ \\
\hline
\end{tabular}

*Values are not mutually exclusive

\section{Discussion:}

In this study, mean age of the participants was $35.17 \pm 6.14$ years. Highest participation was observed from 15-24 years age group. Highest number of the cranial forms of TB, which was tuberculoma (52.2\%) in this study, was also found in the same age group. Spinal TB was found in 25-34 years age group in highest number, all but one were Potts disease. $53 \%$ of the participants were male and $47 \%$ were female, with a male female ratio of 1.13: 1 . The study is consistent with a prospective Canadian cohort study of 82,764 patients with tuberculosis where CNS-TB cases were observed significantly among younger population; however female sex were mostly affected in this study (Phypers M et al 2006). Another study conducted in Turkey, Istanbul consisting of 23 pathologically proven cases of tuberculomas between 1988 and 2003 shows those patients' ages varies from 3 to 67 years with a mean of 31.8 years (Bayindir C et al 2006). While it is observed that the data from all these studies is consistent with the age group in present study, difference is noted in sex distribution of the patients as males are more affected than females in either cranial $(56.5 \%)$ or spinal $(43.5 \%)$ forms of TB in the present study. This discrepancy might be due to factors influencing epidemiological or social differences, like males having chance of more exposure than females and others and perhaps due to larger numbers of male enrollment in the present study.

In the present study, fever was the most common symptom noted in all forms of CNS TB patients $(78.26 \%$ for brain and $71.43 \%$ for spinal cord TB patients). This observation is very much typical of CNS TB and consistent with almost all studies conducted on CNS TB where about $60-90 \%$ of patients had fever as the main presenting complaint of cranial TB. (Thwaites $G$ et al 2009) Headache, loss of consciousness and vomiting were the next three common symptoms of tuberculous meningitis and tubercuoma. Non productive cough and systemic malaise with weight loss and anorexia were noted in $9-13 \%$ patients. History of previous TB (treatment completed) and contact with known TB case were also observed (in $8.70 \%$ and $4 \%$ patients, respectively) in the present study. This is consistent with the data from another study where a history of 
tuberculosis is elicited in approximately $10 \%$ of patients (Sutlas, P. N. et al 2003). A history of tuberculosis was also observed in $14.7 \%$ patients in the study conducted in Italy (Kilani B et al 2003).

Duration of presenting symptoms in cases of cranial TB varied from one week to a period of more than two months; however, a significant number of patients had short history of 7 days to two weeks (39.13\%). This is consistent with an Australian study of 58 patients of TBM where the duration of presenting symptoms varied from 1 day to 9 months and $55 \%$ presented with less than 2 weeks of symptoms (Thwaites G et al 2000).

The most common clinical sign in patients of brain TB elicited in current study is sign of meningeal irritation (65.22\%), mostly neck rigidity, which was found not only in meningitis patients but also in patients of tuberculoma. Cranial nerve palsies, mostly $3^{\text {rd }}$, 6th and $7^{\text {th }}$ cranial nerves and papillodema on fundoscopy were the next two common symptoms. These findings are almost consistent with recent studies (Cherian A et al 2011, Thwaites G et al 2009).

In case of spinal form of TB, weakness of lower limbs was observed in the same percentage of patients having fever (71.43\%). Definite sensory level and gibbus were found in a number of patients. However, some studies suggest that the incidence of paraparesis in patients with Pott's spine varies from $27 \%$ to $47 \%$ (Cherian A et al 2011).

In the present study, high ESR $\left(>50 \mathrm{~mm} 1^{\text {st }}\right.$ hour) was found to be more frequent in spinal forms $(71.43 \%)$ than the cranial forms. It is contradictory to some previous studies that a raised ESR is not a very common finding for CNS TB patients (Thwaites $G$ et al 2009).In this study, high ESR findings among the brain TB patients may be explained by associated lung diseases or in some cases disseminated forms of the disease; but explanation for raised ESR in spinal TB patients remains obscure as these patients did not have any pulmonary or systemic involvement.
Studies indicate that about $50 \%$ of patients with TBM have chest $\mathrm{X}$-rays suggesting active or previous pulmonary tuberculosis while $10 \%$ have miliary disease.(Thwaites G et al 2009).This is very much consistent with the present study where military mottling shadowing (13.04\%) and non-homogeneous patchy opacities in both lung fields (13.04\%) were the commonest chest X-ray finding of cranial TB patients.

ADA level in CSF of tuberculous meningitis patients in this study was found to be positive in $36.36 \%$ patients. A trial comparing concentrations of adenosine deaminase in the CSF of different meningitis patients showed universally raised concentrations in TBM (Thwaites G et al 2000). On the other hand, several other studies could not demonstrate a distinction between TBM and bacterial meningitis by ADA alone.(Rock R.B. et al 2008).

The MRI findings of 12 proved cases of CNS tuberculosis were reviewed in a study in Paris, France where several types of lesions were identified: tuberculomas (58.3\%), leptomeningitis (41.67\%), infarction (33.3\%), abscesses (25\%), hydrocephalus (25\%) (Boukobza M et al 1999) .This study is partially consistent with the present study in that the most frequent imaging finding $(47.82 \%)$ in this study is multiple ring enhancing lesions of variable sizes in different areas having different intensities (MRI) or densities (CT), suggesting tuberculomas. In the current study, most of the tuberculomas were located supratentorially, with the commonest site being the fronto-parietal lobes of cerebral hemispheres, followed by the thalamus, basal ganglia, periventricular region, occipital lobe and both cerebellar hemispheres with brain stems in descending order of frequency. Similarity to this study was noted in the study in Istanbul, Turkey (Bayindir C. et al 2006)

Paraspinal mass with vertebral fracture and reduction of joint space causing cord compression was the most common MRI finding $(85.71 \%)$ in spinal TB cases in this study which is consistent with other studies conducted on spinal TB cases. Non-osseous spinal cord TB is very rare, even in geographical areas where tuberculosis is endemic. (Devi B I et al 2002) 


\section{Conclusion:}

This study has highlighted the relative frequency of various types of brain and spinal TB lesions along with the symptoms, signs and laboratory findings in Bangladeshi adult patients. As brain biopsy and histopathology is not available even in many tertiary level hospitals in Bangladesh, diagnosis of brain TB in particular was done largely on the basis of compatible clinical features, morphological features on CT scan / MRI of brain and/or CSF findings. However, CT guided FNAC from paraspinal soft tissues in cases of osseous spinal TB (Pott's disease) and from paratracheal lymph nodes as well as fine needle aspiration cytology (FNAC) from cervical lymph node were possible. In Bangladesh, tuberculosis should be always an important differential diagnosis in patients of fever with headache as well as spastic paraplegia or quadriplegia for any duration in any sex group.

\section{References:}

1. Ahuja GK, Mohan KK, Prasad K, Behari M. Diagnostic criteria for tuberculous meningitis and their validation. Tubercle Lung Dis, 1994,75, pp.149-52.

2. Bayindir C., Mete O., Bilgic B. Retrospective study of 23 pathologically proven cases of central nervous system tuberculomas. Clinical Neurology and Neurosurgery,2006,08(4),pp.353-357.

3. Boukobza M, Tamer I, Guichard JP, Brunereau L, Polivka M, Leibinger F, Reizine D, Merland JJ. Tuberculosis of the central nervous system-MRI features and clinical course in 12 cases. Journal de Neuroradiologie, 1999,26(3),pp.172-18.

4. Cherian A, Thomas SV. Central nervous system tuberculosis. African Health science, March 2011, 11(1),pp. 116-127

5. Garg R.K., Tuberculosis of the central nervous system. Postgrad Med J,1999,75, pp.133- 140.

6. Jacobs R.F. and Starke, J.R., Mycobacterium tuberculosis. In: Long, S.S., Pickering, L.K. and Prober, C.G. Eds. Principles and practice of pediatric infectious diseases. Vol 2 3rd ed. New York: Churchill Livingstone, 2003,pp. 99

7. Jain S.K., Kwon P., Moss W.J. Clin. Pediatr. (Phila),2005,44,pp.443-450.

8. Kilani B, Ammari L, Tiouiri H, Goubontini A, Kanoun F, Zouiten F, et al. Neuroradiologic manifestations of central nervous system tuberculosis in 122 adults. La Revue de Médecine Interne,2003,24 (2),pp.86-96

9. Nicholas A., Kim K.S., Bishai W.R., Jain S.K. Pathogenesis of Central Nervous System Tuberculosis.Current Molecular Medicine,2009,19 (2).pp.94-99.

10. Phypers M., Harris T., Power C. CNS tuberculosis: a longitudinal analysis of epidemiological and clinical features. Int J Tubrec Lung Dis,2006,10(1),pp.99103.

11. Rajshekhar V, Chandy MJ. Tuberculomas presenting as isolated intrinsic brain stem masses. $\mathrm{Br} J$ Neurosurg, 1997,11, pp.127-133.

12. Rock R.B., Olin M., Baker C.A., Molitor T.W., Peterson P.K. Central Nervous System Tuberculosis: Pathogenesis and Clinical Aspects. Clinical Microbiology Reviews, Apr. 2008, 21(2),pp. 243-261

13. Sutlas, P. N., Unal A., Forta H., Senol S., Kirbas D.Tuberculous meningitis in adults: review of 61 cases. Infection.,2003, 31,pp.387-391.

14. Talamas $\mathrm{O}$, Del Brutto $\mathrm{OH}$, Garcia-Ramos G.Brainstem tuberculoma. Arch Neurol,1989,46, pp.529-535.

15. Thwaites G, Chau TTH, Mai NTH, Drobniewski F, McAdam K, Farrar J. Tuberculous meningitis. J Neurol Neurosurg Psychiatry. 2000; 68:289-299

16. Thwaites G., Fisher M., Hemingway C. ,Scott G. ,Solomon T., Innes J. British Infection Society guidelines for the diagnosis and treatment of tuberculosis of the central nervous system in adults and children. Journal of Infection,2009,59,pp.167187

17. Trivedi R, Saksena S, Gupta RK. MRI in CNS tuberculosis. Indian $\mathrm{J}$ Radiol. Imaging. Nov 2009,19(4),pp.256-265.

18. Vengsarkar US, Pisipati RP, Parekh B, Panchal VG, Shetty MN. Intracranial tuberculoma and CT scan. $J$ Neurosurg1,986,64,pp.568-574. 